\title{
The Patient with Multiple Mesenteric Cystic Lymhangioma was Treated in Neonatal Period Through Prenatal Diagnosis: Case Report and Literature Review
}

\author{
Ibrahim Akkoyun \\ Department of Pediatric Surgery, Konya Education and Research Hospital, Konya, Turkey \\ Correspondence should be addressed to: İbrahim Akkoyun; ibrahimakkoyun@yahoo.com \\ Received date: 4 December 2013; Accepted date: 7 March 2014; Published date: 11 July 20 \\ Academic Editor: Walentyna Balwierz
}

Copyright (C) 2016. Ibrahim Akkoyun. Distributed under Creative Commons CC-BY 4.0

\begin{abstract}
Mesenteric cystic lymphangiomas are benign congenital tumors characterized by the proliferation of lymphatic channels. There is an uncommon disorder that constitutes $0.5 \%$ of all lymphangiomas and can cause fatal complications such as volvulus, intestinal obstruction and traumatic or spontaneous rupture, requiring emergency surgery. For this reason, prenatal diagnosis is important. We present a three day old newborn with multiple cystic abdominal lymphangioma treated with resection anastomosis through prenatal diagnosis.
\end{abstract}

Keywords: Cystic Lymphangioma; Lymphangioma; Mesenteric Lymphangioma; Penatal Diagnosis

\section{Introduction}

Lymphangiomas are benign congenital tumors characterized by the proliferation of lymphatic channels. They are located in the neck and axilla, in 95 of cases. Mesenteric cystic lymphangioma is very rare, having been reported by almost $0.5 \%$ of all lymphangiomas (1-3). Importantly, it can cause fatal complications such as volvulus, intestinal obstruction and traumatic or spontaneous rupture, requiring emergency surgery (4-6). These complications are generally seen in small children. For this reason, prenatal diagnosis is important as it allows planned delivery and prompt postnatal treatment, and improves prognosis. We present a three day old newborn with multiple cystic abdominal lymphangioma treated earlier with resection of the bowel loop and anastomosis with prenatal diagnosis.

\section{Case Report}

A 31-year old woman, having given birth by caesarean section two times before, admitted to our hospital for control in the 34th week of her 3rd pregnancy. In maternal ultrasonography, thin walled homogeneous cystic masses with smoothbordered were found within the pelvis of

Cite this Article as: İbrahim Akkoyun (2016), “The Patient With Multiple Mesenteric Cystic Lymhangioma Was Treated in Neonatal Perıod Through Prenatal Diagnosis: Case Report And Literature Review", JMED

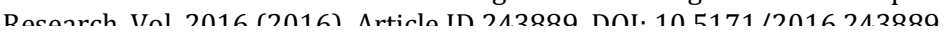


fetus. The largest one was $3.5 \mathrm{~cm}$ diameter (Fig 1). The family was informed of the fact that the infant would be evaluated by a pediatric surgeon after birth and if required, it might be operated. At the end of the pregnancy term, the mother underwent a cesarean section, and a female baby weighing 2700 grams was born. All the physical examination findings of the baby, including abdominal palpation, were normal. All routine blood tests were normal. As a result of abdominal $\mathrm{CT}$, radiologists reported as cystic lesion of $4.5 \times 2 \mathrm{~cm}$ which have thin walled and septas in places. In abdominal ultrasonography, again multiple cysts were observed. After the required preparations for the operation were completed, the newborn was operated in the third day after birth in order to prevent serious complications to be caused by cysts. Under endotracheal general anesthesia, diagnostic laparoscopy was performed through telescope of $5 \mathrm{~mm} 0$ degree via a trocar inserted from the umbilical region. As many cysts had been observed in the mesentery of the ileum, laparotomy was performed as resection and anastomosis was required. During the laparotomy, multiple cysts, the biggest were 4 and $3 \mathrm{~cm}$, located in the mesentery of the distal ileum, were seen (Fig 2). The cysts together with $10 \mathrm{~cm}$ of ileum was resected, and end-toend anastomosis was performed. The postoperative period was uneventful, and the newborn was discharged from the hospital on the postoperative 7 th day. In Gross Pathological Examination, a number of yellow thin walled cysts varying between 0.3 and $4 \mathrm{~cm}$ from which strained looking yellowish liquid is discharged were observed in the mesentery of $10 \mathrm{~cm}$-ileum. In microscopic pathological examination, lymphatic veins, congested vein sections, mononuclear cell infiltration consisting focuses in places were observed in fibromuscular wall of cystic structure covered by endothelium. Diagnosis was reported as mesenteric cystic lymphangioma. Due to the recurrent nature of mesenteric lymphangiomas, the patient was followed at between six month intervals evaluating for her general status and physical development. Abdominal US scan was performed at every visit. Now, she is three years old and is doing well without any abdominal complaints.

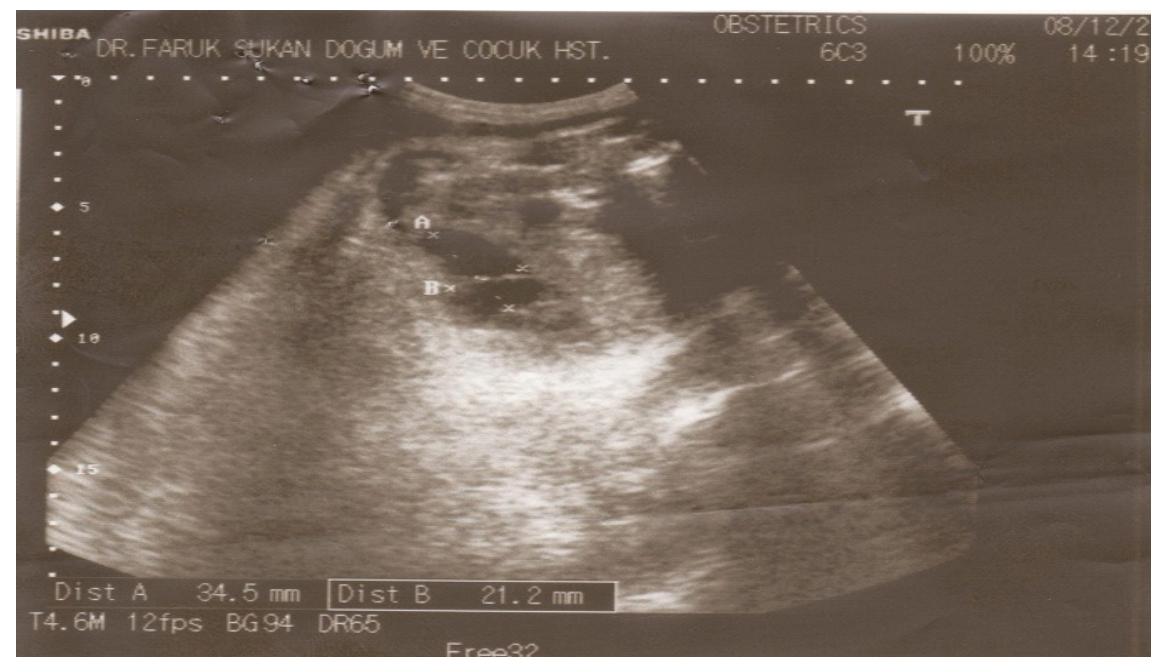

Figure 1: In maternal USG taken in the 35th week of pregnancy, cystic lesions are seen in the pelvis of fetus, the biggest ones of which are 34.5 and $21.2 \mathrm{~mm}$. 


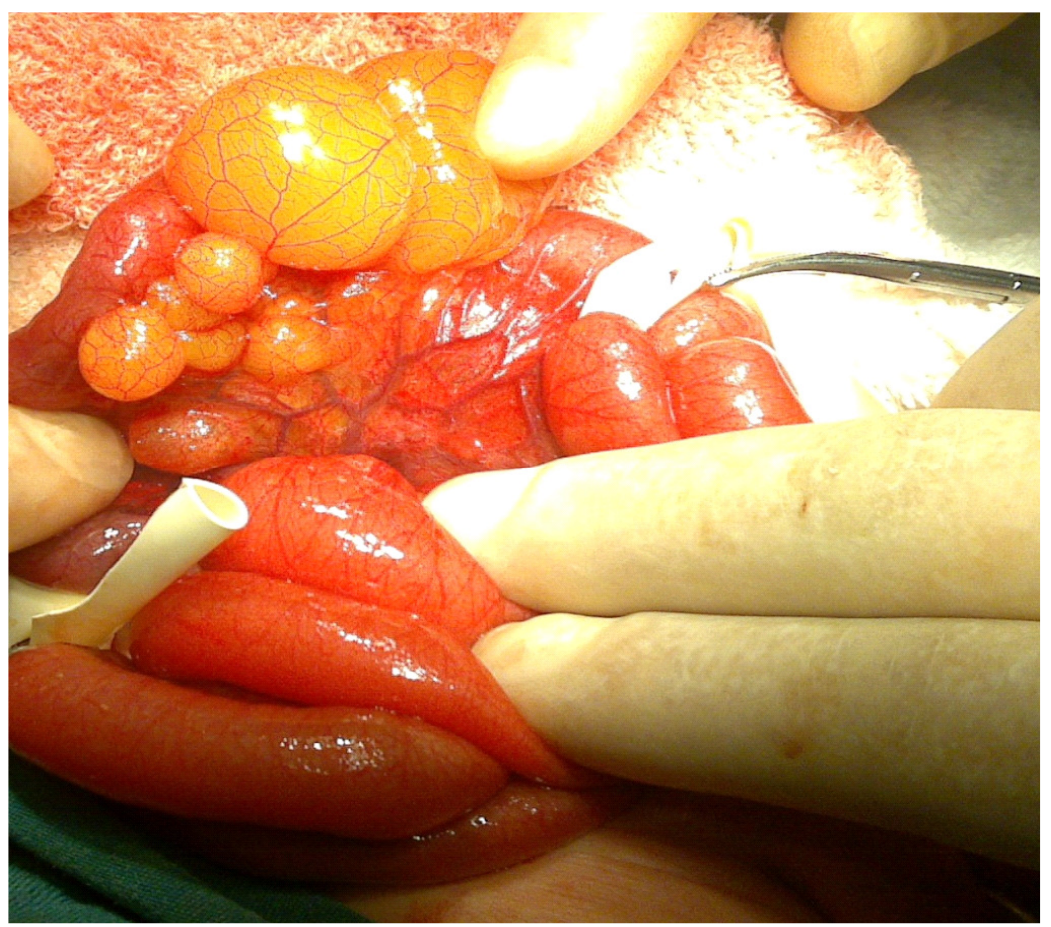

Figure 2: Intraoperative appearance: many cystic lesions the biggest ones of which are 4 and $3 \mathrm{~cm}$ are observed in the mesentery of the ileum.

\section{Discussion}

Lymphangioma is thin walled cystic benign lesions taking root in lymphatic ducts. (2). $90 \%$ of cysts are located in head, neck, trunk and extremities. Mesenteric cystic lymphangiomas constitute nearly $0.5 \%$ of all lymphangiomas, and these are generally located in the ileum and its mesentery (1). Approximately, $60 \%$ of mesenteric cystic lymphangioma is diagnosed within the first year (7). However, some may cause such life threatening complications as volvulus, intestinal obstruction and traumatic or spontaneous rupture (4-6). Therefore, early diagnosis and treatment are of vital importance.

The diagnosis of mesenteric lymphangioma is usually made histologically following the surgical resection of the cyst. Radiological investigations using US or CT usually confirm the presence of a mass and may help to exclude other causes of intraabdominal masses, but are usually insufficient to provide a definite diagnosis. Magnetic resonance imaging (MRI) is also considered to be a suitable investigation for defining the origins of the mass and thus aid diagnosis (8-11)

Nowadays, thanks to the technological development and experience, some diseases may diagnose over the prenatal period. Hence, researching in detail and the early treatment of intraabdominal cysts and masses after birth are possible. In English literature, a patient with very big cystic lymphangiomas in neck, thorax and stomach received prenatal diagnosis and pregnancy was terminated. (12). Moreover, we found that only one case with mesenteric multiple cystic lymphangioma that was diagnosed over the prenatal period and was successfully treated in newborn period (13). According to our knowledge, we report the second case that was successfully treated by resection and anastomosis for multiple mesenteric cystic lymphangioma with prenatal diagnosis. Furthermore, we operated the patient while she was only 3 days old. Postpartum early diagnosis and surgical treatment became possible with prenatal diagnosis; so complications to appear in the future have been prevented. 


\section{References}

1) Alqahtani A, Nguyen LT, Flageole $H$, Shaw K, Laberge JM. (1999) 25 years' experience with lymphangiomas in children. J Pediatr Surg. 34(7):1164-8.

2) Chen CW, Hsu SD, Lin CH, Cheng MF, Yu JC. (2005) Cystic lymphangioma of the jejunal mesentery in an adult: a case report. World J Gastroenterol. 11:5084-5086.

3) Jang JH, Lee SL, Ku YM, An CH, Chang ED. (2009) Small bowel volvulus induced by mesenteric lymphangioma in an adult: a case report. Korean J Radiol. 10:319-322.

4) Hardin WJ, Hardy JD. (1970) Mesenteric cysts. Am J Surg. 119:640-645.

5) Daniel S, Lazarevic B, Attia A. (1983) Lymphangioma of the mesentery of the jejunum: report of a case and a brief review of the literature. Am J Gastroenterol. 78:726-729.

6) Ulman I, Herek O, Ozok G, Avanoğlu A, Erdener A. (1995) Traumatic rupture of mesenteric cyst: a life-threatening complication of a rare lesion. Eur J Pediatr Surg. 5:238-9.

7) Caro PA, Mahboubi S, Faerber EN. (1991) Computed tomography in the diagnosis of lymphangiomas in infants and children. Clin Imaging. 15(1):41-6.
8) Bliss DP Jr, Coffin CM, Bower RJ, Stockmann PT, Ternberg JL. (1994) Mesenteric cysts in children. Surgery. 115(5):571-7.

9) Konen O, Rathaus V, Dlugy E, Freud E, Kessler A, Shapiro M, Horev G. (2002) Childhood abdominal cystic lymphangioma. Pediatr Radiol. 32(2):88-94. Epub 2001 Dec 18.

10) Traubici J, Daneman A, Wales P, Gibbs D, Fecteau A, Kim P. (2002) Mesenteric lymphatic malformation associated with small-bowel volvulus - two cases and a review of the literature. Pediatr Radiol. 32(5):362-5.

11) Jain S, Upreti L, Bhargava SK, Gupta R, Gupta PK: (2002) Mesenteric lymphangioma: diagnosis by multislice spiral CT. Indian J Radiol Imaging 12:580582.

12) Giacalone PL, Boulot P, Deschamps F, Nagy P, Hedon B, Laffargue F, Viala JL. (1993) Prenatal diagnosis of a multifocal lymphangioma. Prenat Diagn. 13:1133-7.

13 ) Santo S, Marques JP, Veca P, Melo A, da Graça LM. (2008) Prenatal ultrasonographic diagnosis of abdominal cystic lymphangioma: a case report. J Matern Fetal Neonatal Med. 21(8):565-6 